\title{
REPRESENTAR, AVALIAR E IMAGINAR EM TEMPOS DE ELEIÇÃO POLÍTICA
}

\author{
(Representing, evaluating and imagining in times of electoral campaigning)
}

\author{
Jéssica Cantele de Freitas ${ }^{1}$ \\ Universidade Federal de Santa Maria \\ Sara Regina Scotta Cabral ${ }^{2}$ \\ Universidade Federal de Santa Maria
}

\section{RESUMO}

Este trabalho objetiva investigar como os candidatos à presidência da República do Brasil constroem representações, avaliações e imaginários acerca de si mesmos, do Brasil e dos brasileiros em um excerto do último debate televisivo presidencial de 2018. O aparato teórico-metodológico é a Linguística SistêmicoFuncional (HALLIDAY; MATTHIESSEN, 2014) e concepções de discurso político de Wodak (2009) e Bochett et al. (2017). Evidenciamos uma predominância do imaginário de mudança, em que a maioria dos candidatos se vê como agente perseverante e capaz dessa transformação, e apenas um deles indica o povo como fator importante dessa questão.

Palavras-chave: Discurso político. Linguística Sistêmico-Funcional. Debate presidencial. Representações. Avaliações. Imaginários.

\begin{abstract}
This work aims at investigating how presidential candidates in Brazil construct representations, evaluative stances and imaginaries about themselves, Brazil and Brazilians in a passage from the last televised presidential debate in 2018. The theoretical and methodological frameworks are based on Systemic Functional Linguistics (HALLIDAY; MATTHIESSEN, 2014) and Wodak's (2009) and Bochett's (2017) notions of political discourse. The predominance of an imaginary of change, in which most candidates see themselves as a persevering and capable agent who will conduct this transformation, was evidenced. Only one of the candidates considers Brazilian citizens as important factors in this process of change.
\end{abstract}

Keywords: Political discourse. Systemic Functional Linguistics. Presidential debate. Representations. Appraisal. Imaginaries.

\section{RESUMEN}

Este trabajo objetiva investigar como los candidatos presidenciales de la Republica de Brasil construyen representaciones, evaluaciones e imaginarios sobre sí mismos, sobre Brasil y brasileños en un extracto del último debate presidencial televisado de 2018. El soporte teórico-metodológico es la Lingüistica Sistémico Funcional (HALLIDAY; MATTHIESSEN, 2014) y concepciones de discurso político de Wodak (2009) y Bochett et al. (2017). Evidenciamos un predominio del imaginario de cambio, en el cual la mayoría de los candidatos se ven a si mismos como agentes perseverantes y capaces de esta transformación. Solo uno de ellos indica las personas como factor importante en este tema.

\footnotetext{
${ }^{1}$ Doutoranda em Estudos Linguísticos pelo Programa de Pós-Graduação em Letras da Universidade Federal de Santa Maria, integrante do Grupo do CNPq SAL (Sistêmica, Ambiente e Linguagens) e pesquisadora dos grupos Mídia, Política e Gramática Sistêmico-Funcional e Núcleo de Estudos em Língua Portuguesa (NELP). Bolsista da Coordenação de Aperfeiçoamento de Pessoal de Nível Superior - Brasil (CAPES) - Código de Financiamento 001. Contato: jeh.cantele@hotmail.com.

${ }^{2}$ Doutora em Letras pela Universidade Federal de Santa Maria, com pós-doutoramento pela Pontifícia Universidade Católica de São Paulo. Professora do Curso de Letras e do Programa de Pós-Graduação em Letras da Universidade Federal de Santa Maria, integrante do grupo do CNPq SAL (Sistêmica, Ambientes e Linguagens) e da Associação de Linguística Sistêmico-Funcional da América Latina (ALSFAL) e coordenadora dos grupos Mídia, Política e Gramática Sistêmico-Funcional e Núcleo de Estudos em Língua Portuguesa (NELP). Contato: sara.scotta.cabral@gmail.com.
} 
Palabras clave: Discurso político. Lingüística Sistémico Funcional. Debate presidencial. Representaciones. Evaluaciones. Imaginario.

Recebido em: dezembro 2019

Aceito em: junho 2020

DOI: $10.26512 /$ les.v21i1.28412

\section{INTRODUÇÃO}

Em tempos de período eleitoral, há um bombardeio de informações e declarações políticas nos mais variados meios de divulgação. Nesse cenário, são diversos os discursos construídos para tentar convencer os eleitores, e os veículos midiáticos abrem espaço para as falas de candidatos em diversos meios, como $\mathrm{TV}$, rádio e internet. Os debates televisivos entre candidatos à presidência do país assumem papel de destaque e contam com grande audiência, uma vez que o que está em jogo é o alcance do mais alto cargo da República. Na ocasião, os candidatos acionam diversas estratégias discursivas para tentar se mostrar a melhor opção de voto.

Dessa forma, torna-se fundamental a análise criteriosa das escolhas linguísticas utilizadas pelos presidenciáveis, os quais utilizam diversos recursos, tais como representações, avaliações e imaginários. Esses recursos linguísticos empregados em seus discursos contribuem para a construção das imagens que eles tentam passar para o público telespectador. Com base nisso, este artigo toma como objeto de estudo a seção denominada "Considerações Finais" do debate presidencial transmitido pela Rede Globo no período eleitoral brasileiro de 2018, de que participaram sete candidatos.

Nosso objetivo principal é investigar "como os candidatos à presidência da República do Brasil constroem representações e avaliações para se mostrarem a melhor opção de voto do país e quais são os seus imaginários para o possível governo". Considerando que os políticos pretendem governar para a população brasileira, elegemos, para análise de representações, avaliações e imaginários, três categorias: (1) o próprio candidato, (2) o povo, (3) o país.

A análise tem por base os preceitos da Linguística Sistêmico-Funcional, especificamente o sistema de transitividade (HALLIDAY; MATTHIESSEN, 2014) e o sistema de avaliatividade (MARTIN; WHITE, 2005), a concepção de discurso político de Wodak (2009), adicionada à de Bochett et al. (2017), e a noção de imaginários políticos de Jessop (2010, 2013). Para organizar este artigo, primeiramente, apresentamos os pressupostos teóricos que fundamentam a pesquisa, seguidos pelos procedimentos metodológicos empregados na realização da análise. Na sequência, 
apresentamos os resultados evidenciados e as discussões referentes a eles e, por fim, expomos as considerações finais.

\section{FUndamentaÇão TeÓRICA}

\subsection{Discurso Político}

As características que remetem ao discurso político são amplas e variadas, uma vez que existem diversas práticas sociais e discursivas envoltas pelo tema "política". Wodak (2009) compreende que os textos que compõem o discurso político vão além daqueles produzidos em situações oficiais do fazer político, abrangendo também aqueles referentes a situações em que políticos discursam ou debatem em diversas mídias sobre assuntos de natureza política (WODAK, 2009). Dessa maneira, compreendemos discurso político, neste artigo, como aquele proferido por agentes políticos legitimados sobre assuntos de caráter político em ambientes variados, não apenas o institucional (WODAK, 2009).

Nessa perspectiva, de acordo com o proposto por Bochett et al. (2017), podem ser atribuídas três diferentes classificações para os discursos dessa esfera, os quais se distinguem principalmente em relação a sua finalidade, ao âmbito em que ocorrem e à legitimidade dos agentes envolvidos. São elas: discurso político (DP), discurso do político (DDP) e discurso sobre política (DSP). De acordo com os autores, o DP é aquele cujos agentes que o empregam são detentores de ação política, restritos ao âmbito institucional parlamentar, ou midiáticos, e caracteriza-se por prover ação política, para vir a se tornar lei ou norma. O DDP é aquele empregado por agentes legitimados, mas direcionados aos eleitores da nação, visando persuadir os interlocutores ou solicitar votos e apoio. Por fim, o DSP é aquele produzido em resposta a acontecimentos dessa esfera pela mídia, e visa apresentar informações ou posicionamentos sobre fatos desse cenário para a população (BOCHETT et al., 2017).

A partir dessa distinção proposta por Bochett et al. (2017), centramo-nos na concepção de discurso do político (DDP), visto que o objeto de análise refere-se a um debate político televisionado, o qual foi realizado por agentes legitimados e direcionado à nação.

É importante observar também que, em programas pré-eleitorais, é comum os candidatos fazerem projeções para seu futuro governo, de modo a tentar angariar votos da audiência. É o que Wodak (2009), em determinados momentos de seu estudo, denomina imaginários políticos. Aprofundando esse conceito, a autora baseia-se nos pressupostos de Jessop (2010; 2013), para quem os imaginários são "sistemas semióticos que enquadram a experiência de indivíduos de um mundo 
desordenadamente complexo e/ou informam cálculos coletivos sobre esse mundo" "3 (JESSOP, 2010, p. 344). Ou seja, os imaginários referem-se ao sentido expresso pela experiência passada e/ou pela projeção de futuro de um sujeito em relação ao seu contexto.

O foco de Jessop (2013) consiste nos imaginários econômicos, mas, segundo o autor, existem muitos outros, os quais estão envolvidos em relações complexas e confusas em diferentes locais, pois “sem eles, indivíduos não podem 'continuar' no mundo e os atores coletivos (como as organizações) não podem se relacionar com seus ambientes, tomar decisões ou buscar estratégias mais ou menos coerentes" ${ }^{4}$ (JESSOP, 2013, p. 3). Além disso, os imaginários surgem quando se pretende redefinir projetos e visões, envolvendo, entre as principais forças, partidos políticos, grupos de reflexão, órgãos importantes, interesses organizados, movimentos sociais e meios de comunicação de massa.

A partir do exposto, compreendemos que os imaginários são importantes nos discursos da esfera política, uma vez que, ao projetar "cálculos coletivos" sobre o mundo em que vivem, os sujeitos políticos orientam o andamento dos acontecimentos nesse âmbito.

\subsection{Linguística Sistêmico-Funcional}

A Linguística Sistêmico-Funcional (LSF) corresponde a uma teoria que compreende o funcionamento da linguagem incidindo sobre o social (HALLIDAY; MATTHIESEN, 2014). Nessa perspectiva, a linguagem é sociossemiótica, uma vez que sua abordagem abarca o estudo de um sistema de significados produzidos em um contexto social, por meio de relações, o que constitui, desse modo, a cultura humana (HALLIDAY; HASAN, 1985). Em relação a essa teoria, interessanos, nesta pesquisa, a metafunção ideacional (HALLIDAY; MATTHIESSEN, 2014) e o sistema de avaliatividade (MARTIN; WHITE, 2005), que serão apresentados a seguir.

Uma das funções da linguagem consiste na expressão de experiências reais e experiências de nossa consciência. Quando a linguagem é utilizada como forma de codificar nossa experiência no mundo, estamos no domínio da metafunção ideacional. Quando analisamos como os textos representam as pessoas, coisas e acontecimentos em um campo da atividade social, centramo-nos na função experiencial, um dos domínios dessa metafunção (HALLIDAY; MATTHIESSEN, 2014). O sistema que se refere a essa metafunção é o de transitividade, em que são compreendidas as ações,

\footnotetext{
${ }^{3}$ No original: "Imaginaries are semiotic systems that frame individual subjects' lived experience of an inordinately complex world and/or inform collective calculation about that world".

${ }^{4}$ No original: "Without them, individuals cannot 'go on' in the world and collective actors (such as organizations) could not relate to their environments, make decisions, or pursue more or less coherent strategies".
} 
quem participa delas e em quais circunstâncias (HALLIDAY; MATTHIESSEN, 2014). Trata-se de um sistema de descrição da oração, em que seus elementos formam uma figura com três componentes: processo, elemento central da oração; participantes, entidades envolvidas; circunstâncias, que expandem o processo em relação a modo, tempo e lugar, por exemplo. Cada oração possui seus participantes, e as circunstâncias podem permear todos os tipos de oração.

Há seis tipos de significados de processos, o que resulta em seis tipos de orações, são elas: material - fazer e acontecer; relacional - caracterizar e identificar; mental - pensar e sentir; verbal dizer; comportamental - comportar-se; e existencial - existir (HALLIDAY; MATTHIESSEN, 2014). Restringimo-nos, nesta seção, apenas à apresentação dos tipos de processos, os quais possuem seus participantes correspondentes, que serão apresentados e descritos conforme cada um for aparecendo nos resultados, na seção 4.

Além de permitir a identificação de representações de experiências, a linguagem fornece mecanismos para o alcance de diversos outros propósitos, entre eles, a verificação de opiniões e posicionamentos expressos por falantes/escritores de diferentes textos em diversos eventos sociais. Nesse viés, o sistema de avaliatividade (MARTIN; WHITE, 2005) está calcado em um conjunto de significados interpessoais e busca, a partir de escolhas disponibilizadas pelo sistema linguístico, sistematizar os valores atribuídos a pessoas e seus comportamentos e os valores atribuídos a objetos e a eventos (MARTIN; WHITE, 2005). Assim, constitui-se de três subsistemas: atitude, engajamento e gradação, os quais apresentam subdivisões (MARTIN; WHITE, 2005). Nesta pesquisa, interessanos o subsistema atitude, que é preocupado com avaliações sobre indivíduos e seus comportamentos, eventos ou coisas, com valores de emoção, ética e estética, recobrindo afeto, julgamento e apreciação.

O afeto refere-se à avaliação de sentimentos, tanto positivos quanto negativos, e dá conta de três regiões semânticas: in/felicidade, in/segurança e in/satisfação. Já o julgamento relaciona-se às avaliações de aprovação ou reprovação de comportamentos e pode ser classificado em estima social (capacidade, normalidade e tenacidade) e sanção social (veracidade e propriedade). Por fim, a apreciação avalia fenômenos semióticos e naturais, e pode ocorrer por reação, composição ou valoração (MARTIN; WHITE, 2005). Apresentamos essas regiões semânticas e suas subdivisões na Figura 1. 


\section{Figura 1: Subsistema de Atitude}

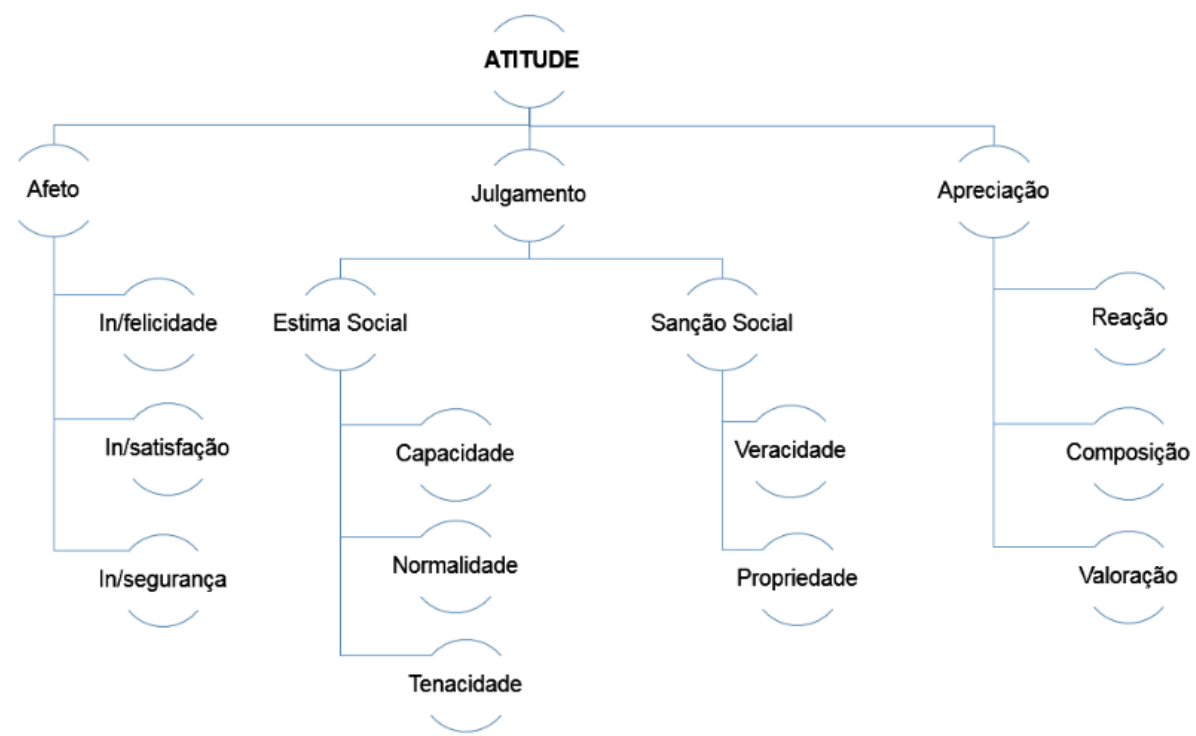

Fonte: Freitas e Cabral (2018, p. 235), a partir de Martin e White (2005).

Expostos os preceitos teóricos que embasam esta pesquisa, passamos a apresentar, na seção seguinte, os procedimentos metodológicos adotados para a realização da análise.

\section{Metodologia}

Em virtude do contexto e do objetivo da pesquisa em questão, consideramos o debate político televisivo como o tipo de discurso linguístico ideal para a verificação da construção de imagens e de imaginários que os políticos pretendem transmitir com vistas à conquista do voto dos telespectadores. Nesse viés, delimitamos como objeto inicial de análise o debate transmitido pela Rede Globo no período eleitoral de 2018, disponível no site da emissora ${ }^{5}$.

A escolha pelo debate da emissora em questão decorreu do fato de ter sido o último antes do primeiro turno das eleições de 2018, uma vez que, nesse ano, não houve debates referentes ao segundo turno. Considerando a extensão da transcrição do debate, foi necessário realizar um recorte para esta análise, de modo que optamos pela seção "Considerações Finais". A seleção desse trecho consistiu no fato de que esse é o momento em que os políticos dirigem a sua mensagem diretamente aos eleitores da nação, com o propósito de justificar o porquê de sua candidatura. Dessa maneira,

\footnotetext{
${ }^{5}$ Disponível em: https:/g1.globo.com/politica/eleicoes/2018/noticia/2018/10/05/veja-a-integra-do-debate-naglobo.ghtml.
} 
compreendemos que eles aproveitam a oportunidade de construir uma imagem positiva de si e de se mostrar como a melhor opção para resolver os problemas do povo e do país.

Desse modo, o corpus de análise ficou constituído pela transcrição da seção "Considerações Finais" do debate político transmitido pela Rede Globo, no dia 04/10/2018. Especificamente, analisamos a fala dos sete candidatos que estavam presentes: Geraldo Alckmin (PSDB); Alvaro Dias (Podemos); Ciro Gomes (PDT); Henrique Meirelles (MDB); Fernando Haddad (PT); Marina Silva (Rede) e Guilherme Boulos (PSOL), nessa ordem, respectivamente.

A fim de atingir o objetivo proposto, desenvolvemos a análise no corpus selecionado em três blocos:

a) Exame das representações construídas pelos entrevistados;

b) Exame das avaliações realizadas pelos entrevistados;

c) Identificação dos imaginários construídos pelos candidatos.

Para os dois primeiros blocos, elegemos três categorias de análise: (a) o próprio candidato, (b) o povo e (c) o país, de modo a analisar como representações e avaliações perpassam os discursos dos candidatos.

No primeiro bloco, o exame das representações foi feito percorrendo a seguinte trajetória: (i) segmentação do texto em orações; (ii) seleção daquelas referentes a cada uma das categorias elencadas; (iii) análise do sistema de transitividade (HALLIDAY; MATTHIESSEN, 2014); (iv) cômputo dos resultados. Já no segundo bloco, fizemos o mesmo caminho após a segmentação do texto em orações: (i) seleção das marcas de avaliatividade (MARTIN; WHITE, 2005) referentes a cada uma das três categorias (o candidato, o país, o povo); (ii) análise das marcas pelas categorias do subsistema atitude do sistema de avaliatividade; (iii) categorização das ocorrências; (iv) cômputo dos resultados. No terceiro bloco, o exame dos imaginários apresentados pelos candidatos, buscamos localizar algumas marcas linguísticas que evidenciassem projeções de futuro dos sujeitos em relação ao seu contexto.

Para cumprirmos a trajetória de pesquisa aqui apresentada, utilizamos tanto recursos quantitativos como recursos qualitativos, em que os primeiros serviram como ponto de partida para a interpretação dos dados obtidos. Sabemos que, por meio de procedimentos quantitativos, enfatizamos o "ato de medir e de analisar as relações causais entre variáveis" (DENZIN; LINCOLN, 2006, p. 23), ou seja, categorizamos as ocorrências linguísticas investigadas de forma numérica, com foco nas ocorrências predominantes. De posse desses e por meio de procedimentos qualitativos, estamos aptos a evidenciar as interpretações por eles expressas, com "ênfase sobre as qualidades das entidades" (DENZIN; LINCOLN, 2006, p. 23).

Na seção a seguir, apresentamos os resultados obtidos em nossa análise. 


\section{ANÁlise e DiscuSsão dos ReSUltados}

Para apresentarmos a análise e a interpretação dos resultados, dividimos esta seção em três subseções: análise do sistema de transitividade; análise do sistema de avaliatividade e análise dos imaginários, conforme os blocos que expusemos na metodologia.

\subsection{Análise do sistema de transitividade}

Efetuados os passos apontados na metodologia e computados os dados obtidos após a seleção das orações e respectiva categorização, obtivemos os resultados quantitativos que apresentamos no Quadro 1.

\section{Quadro 1: Ocorrência de participantes ${ }^{6}$}

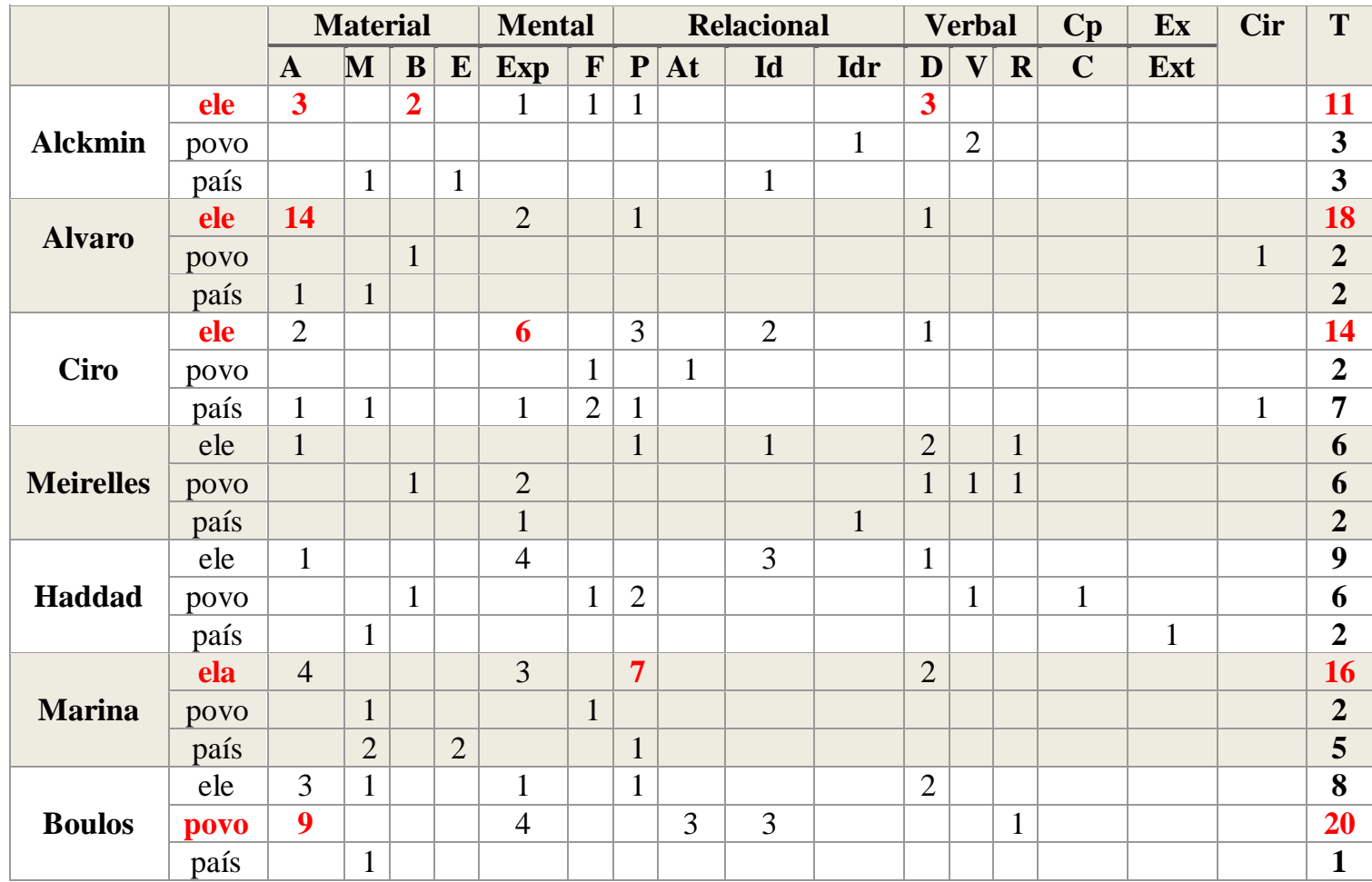

Fonte: Elaborado pelas autoras.

\footnotetext{
${ }^{6} \mathrm{~A}=$ Ator; $\mathrm{M}=$ Meta; $\mathrm{B}=$ Beneficiário $\mathrm{E}=\mathrm{Escopo} ; \mathrm{Exp}=$ Experienciador $\mathrm{F}=$ Fenômeno; $\mathrm{P}=$ Portador; At= Relacional; $\mathrm{Id}=$ Identificado; $\mathrm{Idr}=$ Identificador; $\mathrm{D}=$ Dizente; $\mathrm{V}=$ Verbiagem; $\mathrm{R}=$ Receptor; $\mathrm{C} \mathrm{p}=$ Comportamental; $\mathrm{C}=$ Comportante; Ex= Existencial; Ext= Existente; Cir= Circunstância; T= Total.
} 
Tomando como ponto de partida o Quadro 1, estabelecemos como ponto de corte o número de 10 ocorrências a serem consideradas para comentários quanto à função exercida pelos entrevistados quando representando a si mesmos, o país e o povo, haja vista que o mesmo tempo, em minutos, foi concedido a todos os convidados. Pelo cômputo obtido, observamos que Alckmin, Alvaro, Ciro, Marina e Boulos foram aqueles que mais investiram o seu tempo nas representações que analisamos.

Ao falar de si próprio, em 11 orações, as escolhas linguísticas de Alckmin revelam uma autorrepresentação predominantemente como Ator (3), Dizente (3) e Beneficiário (2). Ao representarse como Ator, Alckmin revela ser um participante ativo, que investe energia para a realização da ação; como Dizente, a representação é de alguém que fala; e como Beneficiário, de alguém que se beneficia do processo. Exemplos dessas ocorrências são ilustrados em (1), (2) e (3).

\begin{tabular}{|l|l|}
\hline Ex. 1 & Percorri o Brasil do Oiapoque ao Chuí, todas as regiões do Brasil. \\
\hline Ex. 2 & Peço o seu voto \\
\hline Ex. 3 & e a minha querida Lu, esposa há 40 anos, que nos acompanhou em toda esta jornada. \\
\hline
\end{tabular}

O Exemplo (1) refere-se à oração material em que Alckmin desempenha o papel de Ator do processo, indicando o seu investimento de energia para desenvolver a ação: percorrer todo o país. No Exemplo (2), verificamos o processo verbal “peço”, em que Alckmin desempenha o papel de Dizente, solicitando verbalmente o voto do público eleitor que o assiste. Por fim, no Exemplo (3) há o processo material "acompanhou", em que Alckmin desempenha o papel de Beneficiário da ação exercida pela sua esposa. Essas escolhas linguísticas denotam que Alckmin autorrepresenta-se do seguinte modo: um candidato que age pelo país, precisa do povo e é auxiliado.

Em relação às representações atribuídas ao povo, 3 ocorrências, a predominância se deu por Verbiagem (2), que se refere ao conteúdo do que é dito em processos verbais. Isso pode ser verificado no Exemplo (2) acima, em que o pronome "seu" refere-se à população, ou seja, o participante "povo" encontra-se dentro da Verbiagem, dando pouco destaque para esse participante.

Quanto às representações do país (3 ocorrências), não houve a predominância de nenhum participante específico, havendo uma ocorrência de cada participante: Meta, Escopo e Identificador. Como Meta, Alckmin representa "o país” como um participante que é impactado pela ação; como Escopo, um participante que está ligado ao processo, mas não é afetado por ele; como Identificado, como um participante que recebe uma identidade, ou seja, uma característica que é própria. Esses participantes podem ser verificados nos Exemplos (4), (5) e (6). 


\begin{tabular}{|l|l|}
\hline Ex. 4 & Acumulei experiência e espírito público para trabalhar pelo Brasil \\
\hline Ex. 5 & Percorri o Brasil \\
\hline Ex. 6 & "O melhor produto do Brasil ainda continua sendo os brasileiros". \\
\hline
\end{tabular}

No Exemplo (4), o processo material "trabalhar" denota o impacto que o país recebe pelo participante Ator, ou seja, a representação é a de que Alckmin agirá sobre o país. Em (5), Brasil é o Escopo, uma vez que está ligado ao processo, mas não sofreu seu impacto. Em (6), por meio do processo relacional "continua sendo", é atribuída uma identidade ao país, que tem o seu povo como o melhor produto.

Ao se referir a si próprio, em 18 orações, Alvaro autorrepresenta-se predominantemente como um participante Ator. O Exemplo (7) ilustra essa representação ativa do candidato, o qual constrói a sua imagem exaltando as ações que realizou enquanto político a favor do país que pretende governar.

Ex. 7 Estou de consciência tranquila, combati corrupção, sim, a minha vida toda, prendi gente como governador, cancelei licitações fraudadas, anulei aposentadorias imorais e acabei com privilégios.

Já em relação ao povo, Alvaro refere-se a ele 2 vezes, representando-o por meio do participante Beneficiário (1) e de Circunstância de acompanhamento (1), que indica com quem a ação será realizada. Esses exemplos encontram-se em (8) e (9).

\begin{tabular}{|l|l|}
\hline Ex. 8 & Trabalharei duro quatro anos para deixar um legado de mudança para o povo brasileiro \\
\hline Ex. 9 & Quero mudar o Brasil com seu apoio \\
\hline
\end{tabular}

Em (8), o povo brasileiro é o Beneficiário do processo material "deixar", que tem Alvaro como o Ator, ou seja, a população será beneficiada pela ação do candidato. Em (9), a Circunstância de acompanhamento "com seu apoio" evidencia que Alvaro precisa do apoio da população para atingir ao seu objetivo de mudar o Brasil.

O país é citado 2 vezes, sendo representado por Alvaro como Meta e como Ator. Como participante Meta verifica-se no Exemplo (9) acima, em que o presidenciável almeja realizar mudanças sobre o país. O Exemplo (10) denota o país enquanto Ator de "muda", evidenciando a sua capacidade de mudança.

\begin{tabular}{|l|l}
\hline Ex. 10 & Eu sei: o Brasil só muda se nós trabalharmos com ética, com correção, com honestidade
\end{tabular} 
O candidato Ciro autorrepresenta-se 14 vezes, com os participantes Experienciador (6) e Portador (3) como predominantes. Ao se representar como Experienciador, Ciro revela ser um participante que experiencia um processo mental, tal como sentir, pensar, perceber ou desejar. Enquanto Portador, por meio de processos relacionais, Ciro atribui-se as próprias características. Exemplificamos em (11) e (12).

\begin{tabular}{|l|l|}
\hline Ex. 11 & Sou ficha limpa, tenho experiência e uma proposta para resolver os problemas brasileiros \\
\hline Ex. 12 & $\begin{array}{l}\text { Ganho do Haddad e do Bolsonaro no segundo turno com grande folga, mas preciso do seu voto } \\
\text { no primeiro turno para ser presidente de todos os brasileiros. }\end{array}$ \\
\hline
\end{tabular}

Em (11), Ciro é o Portador de Atributos que denotam a sua conduta e sua capacidade para governar o país: é ficha limpa, tem experiência e proposta. Já em (12), verifica-se o presidenciável como Experienciador do processo mental cognitivo "preciso", evidenciando que o candidato necessita do povo para ser eleito. O exemplo (12) também ilustra as representações que Ciro atribui ao povo, objeto ao qual ele se refere duas vezes em sua fala, representando-o como Fenômeno (1) e como Atributo (1). Enquanto Fenômeno, o povo complementa o processo "preciso" revelando fazer parte do desejo do Experienciador Ciro, que precisa do seu voto. Como Atributo, o povo complementa o processo relacional "ser", caracterizando o que Ciro pretende ser: presidente de todos os brasileiros.

Em relação ao país, Ciro representa-o 7 vezes, com a predominância do participante Fenômeno (2). Em (13), Brasil é o Fenômeno do processo "permitirá", que tem "aprofundar essa divisão" como Experienciador.

\footnotetext{
Ex. 13 Aprofundar essa divisão simplesmente não permitirá ao Brasil se reconciliar e trabalharmos aquilo que interessa
}

A candidata Marina cita-se 16 vezes em sua fala, sendo predominante as categorias Portador (7), Ator (4) e Experienciador (3). Um exemplo da ocorrência desses três tipos de participantes encontra-se em (14) abaixo. Enquanto Portador, há os processos relacionais "estou" e "sou", que designam suas características: está concorrendo porque é a melhor opção. Como Ator, a candidata destaca a sua capacidade de agir pelo país, através dos processos "governar" e "unir" e, como Experienciador, representa que tem consciência da sua capacidade para unir o país.

Ex. 14 Eu estou aqui porque eu sei que eu sou a melhor pessoa para o unir o Brasil e eu estou pronta para governar o Brasil e unir os brasileiros a favor de um Brasil próspero para todos. 
Em relação ao povo, há a representação em duas orações, uma como Meta e outra como Fenômeno. A Meta está representada no Exemplo (14), atingida pelo processo “unir”, através da ação de Marina, representando que a candidata visa à união dos brasileiros. Enquanto Fenômeno, a candidata ressalta a necessidade do povo: respeito com o seu dinheiro, ilustrada, por meio do pronome “seu”, no Exemplo (15).

Ex. 15 esse país precisa de força moral, precisa de respeito com o seu dinheiro, com a Constituição, com a diversidade religiosa, com a diversidade cultural.

Marina refere-se ao país cinco vezes, representando-o predominantemente como Meta (2) e como Experienciador (2). A Meta também pode ser verificada no Exemplo (14), através dos processos “unir" e "governar", os quais evidenciam a ação de Marina sobre o país. Enquanto Experienciador, a representação relaciona-se à necessidade do país: força moral e respeito com o dinheiro do povo, apresentados no Exemplo (15) acima.

O candidato Boulos se autorrepresentou 8 vezes, com a recorrência dos participantes Ator (3) e Dizente (2). Como Ator, destaca as ações que realizará para mudar o país (Exemplo 16) e, como Dizente, direciona-se aos que estão junto dele para agradecer (Exemplo 17).

\begin{tabular}{|l|l|}
\hline Ex. 16 & $\begin{array}{l}\text { Nós só vamos mudar o Brasil enfrentando de verdade os privilégios e mudando o jeito de fazer } \\
\text { política. }\end{array}$ \\
\hline Ex. 17 & Eu quero agradecer a toda a militância dessa nossa aliança, que construiu junto a jornada até aqui \\
\hline
\end{tabular}

Em relação ao povo, Boulos representa-o em 19 ocorrências, predominando os participantes Ator (9) e Experienciador (4). Enquanto Ator, Boulos dirige-se a ele de forma imperativa, instruindo a forma como devem realizar a ação de votar, ilustrada no Exemplo (18). Como Experienciador, Boulos solicita, por meio de processos cognitivos e desiderativos, que o povo reflita sobre o que deseja para o futuro (Exemplo 19).

\begin{tabular}{|l|l|}
\hline Ex. 18 & Vote com esperança \\
\hline Ex. 19 & Pense no futuro, se você quer um futuro sem direitos, um futuro com a violência e com ódio \\
\hline
\end{tabular}

Quanto ao país, citado apenas uma vez, a representação é a de Meta, que sofrerá a mudança a ser desempenhada pelo participante Ator, Boulos. Essa oração é apresentada no Exemplo (20).

\begin{tabular}{|l|l|}
\hline Ex. 20 & $\begin{array}{l}\text { Nós só vamos mudar o Brasil enfrentando de verdade os privilégios e mudando o jeito de fazer } \\
\text { política. }\end{array}$ \\
\hline
\end{tabular}


Após a análise das representações pelo sistema de transitividade, investigamos as avaliações que os candidatos realizam referente as três categorias (próprio candidato, o país e o povo), as quais expomos na seção a seguir.

\subsection{Análise do sistema de avaliatividade}

Diferentemente das representações, apresentadas na seção anterior, nas falas dos candidatos não foram identificadas avaliações nas três categorias analisadas. Por esse motivo, na análise das ocorrências de avaliatividade, precisamos diminuir o ponto de corte, uma vez que os resultados encontrados foram em número bem inferior aos do sistema de transitividade. Os resultados são apresentados na sequência (Quadro 2).

\section{Quadro 2: Ocorrência de avaliatividade ${ }^{7}$}

\begin{tabular}{|c|c|c|c|c|c|c|c|c|c|}
\hline & \multicolumn{4}{|c|}{ Julgamento } & \multicolumn{2}{|c|}{ Apreciação } & \multirow{3}{*}{$\begin{array}{c}\text { Afeto } \\
\text { Felicidade }\end{array}$} & \multirow{3}{*}{ TOTAL } \\
\hline & & \multicolumn{3}{|c|}{ Estima } & \multirow{2}{*}{$\begin{array}{c}\text { Sanção } \\
\mathrm{P}\end{array}$} & \multirow[t]{2}{*}{$\mathrm{V}$} & \multirow[t]{2}{*}{ Comp. } & & \\
\hline & & $\mathrm{C}$ & $\mathrm{T}$ & $\mathrm{N}$ & & & & & \\
\hline \multirow{3}{*}{ Alckmin } & ele & 1 & 1 & & & & & & 2 \\
\hline & povo & & & & & 2 & & 1 & 3 \\
\hline & país & & & & & & & & $\mathbf{0}$ \\
\hline \multirow{3}{*}{ Alvaro } & ele & & 11 & & 4 & & & & 15 \\
\hline & povo & & & & & & & & $\mathbf{0}$ \\
\hline & país & & & & & & & & $\mathbf{0}$ \\
\hline \multirow{3}{*}{ Ciro } & ele & 4 & & & 1 & & & 4 & 9 \\
\hline & povo & & & & & & & & $\mathbf{0}$ \\
\hline & país & & & & & & 1 & & 1 \\
\hline \multirow{3}{*}{ Meirelles } & ele & 1 & 2 & & 6 & & & & 9 \\
\hline & povo & & & & & & 1 & & 1 \\
\hline & país & & & & & & & & $\mathbf{0}$ \\
\hline \multirow{3}{*}{ Haddad } & ele & & 4 & 5 & & & & & 9 \\
\hline & povo & & & & & & & & $\mathbf{0}$ \\
\hline & país & & & & & & & & $\mathbf{0}$ \\
\hline \multirow{3}{*}{ Marina } & ele & 4 & & & 2 & & & 1 & 7 \\
\hline & povo & & & & & & & & $\mathbf{0}$ \\
\hline & país & & & & & & & & $\mathbf{0}$ \\
\hline \multirow{3}{*}{ Boulos } & ele & 2 & 2 & & & & & & 4 \\
\hline & povo & & & & & & & & $\mathbf{0}$ \\
\hline & país & & & & & & & & $\mathbf{0}$ \\
\hline
\end{tabular}

Fonte: Elaborado pelas autoras.

\footnotetext{
${ }^{7} \mathrm{C}=$ Capacidade $\mathrm{T}=$ Tenacidade $\mathrm{N}=$ Normalidade $\mathrm{P}=$ Propriedade $; \mathrm{V}=$ Valor Comp.= Composição.
} 
O candidato Alvaro realiza avaliações apenas de si próprio, em 15 ocorrências, sendo 11 por julgamento de estima social tenacidade e 4 por sanção social propriedade. O julgamento por estima social tenacidade é exemplificado em (21), em que Alvaro utiliza a expressão "trabalharei duro", para indicar o nível do seu empenho ao governar o país.

Ex. 21 Trabalharei duro quatro anos para deixar um legado de mudança para o povo brasileiro, especialmente para os pobres desse país.

Os julgamentos por sanção social propriedade são aqueles referentes a avaliações de conduta relacionadas a leis e normas de instituições da sociedade. Em (22) observam-se exemplos dessas ocorrências em "combati corrupção", "prendi gente”, “cancelei licitações fraudadas", "anulei aposentadorias imorais" e "acabei com privilégios", o que representa ações que ele realizou que são corretas perante a lei.

\footnotetext{
Ex. 22 Estou de consciência tranquila, combati corrupção, sim, a minha vida toda, prendi gente como governador, cancelei licitações fraudadas, anulei aposentadorias imorais e acabei com privilégios.
}

As avaliações realizadas por Ciro são de si próprio, 9 ocorrências, e do país, 1 ocorrência. Em relação à autoavaliação, a predominância é de avaliação pelas categorias julgamento por estima social capacidade (4) e afeto felicidade (4). A avaliação por capacidade é ilustrada no Exemplo (23), ao evidenciar que é experiente e possui proposta capaz de resolver os problemas brasileiros.

\section{Ex. 23 Sou ficha limpa, tenho experiência e uma proposta para resolver os problemas brasileiros}

As avaliações por afeto felicidade são aquelas que avaliam sentimentos positivos ou negativos em relação ao nível de felicidade. Em (24) essa categoria é representada pela demonstração do desejo de Ciro em relação ao povo brasileiro.

\section{Ex. 24 Eu teria muita vontade de agradecer, de fazer um carinho, de passar o meu olho no meu coração por todo o território brasileiro que eu conheço tão bem, mas esse é o ponto.}

Referente ao país, houve uma avaliação, do tipo apreciação por composição, que avalia o equilíbrio e a complexidade das coisas. Essa avaliação está ilustrada no Exemplo (25), avaliando o país como "parado" e "paralisado por uma crise política". 
Ex. 25 Há quatro anos o nosso país está parado, paralisado por uma crise política assentada no ódio, no desfazimento de um pelo outro, e agora esse filme parece que está querendo se repetir.

Meirelles apresenta avaliações de si próprio em nove ocorrências e do povo em uma ocorrência. Referente a si, as avaliações se dão predominantemente por julgamentos de sanção social propriedade (6) e de estima social tenacidade (2). O Exemplo (26) apresenta exemplos dessas categorias, em que "trabalhei 33 anos" e "dez anos" denotam a tenacidade e "nunca tive uma denúncia de corrupção" evidenciam a sua conduta adequada às leis.

\section{Ex. 26 Eu trabalhei 33 anos em empresas, dez anos em governo e nunca tive uma denúncia de corrupção}

O povo, por sua vez, é avaliado por apreciação composição, ressaltando a necessidade que o país possui: confiança.

\footnotetext{
\begin{tabular}{|l|l} 
Ex. 27 & O que o Brasil precisa agora é de confiança, porque confiança traz crescimento, traz emprego,
\end{tabular} traz renda.
}

O presidenciável Haddad realiza apenas autoavaliações, por meio de julgamentos de estima social tenacidade (4) e normalidade (5). A tenacidade está ilustrada no Exemplo (28), por meio da expressão "vou seguir esse princípio à risca até o fim do meu mandato".

Ex. 28 Aprendi isso com meu pai, vou seguir esse princípio à risca até o fim do meu mandato

A avaliação por estima social normalidade avalia o quão normal o participante é. No Exemplo (29) a estratégia de normalidade é utilizada para indicar o caráter popular do candidato ao apresentar a sua origem.

\section{\begin{tabular}{|l|l} 
Ex. 29 & Sou neto de um líder religioso, sou filho de um agricultor familiar.
\end{tabular}}

A seguir, expomos os resultados da análise do nosso terceiro bloco metodológico, referente às projeções que os candidatos realizaram em seus discursos.

\subsection{Análise dos Imaginários}

Como os imaginários não apresentam categorias pré-definidas, a análise para a sua identificação no corpus se deu pela semântica. Assim, foi realizada uma leitura das falas dos 
candidatos, a fim de identificar marcas linguísticas que remetessem ao futuro, com a ideia de projeção de seus objetivos para o país. Posteriormente, foram atribuídos nomes aos imaginários identificados. Os resultados encontram-se no Quadro 3.

\section{Quadro 3: Identificação de imaginários}

\begin{tabular}{|c|c|c|c|}
\hline CANDIDATO & & EXCERTO & IMAGINÁRIO \\
\hline Alckmin & Ex. 30 & $\begin{array}{l}\text { Peço o seu voto para que a gente saia desse triste } \\
\text { resultado que tem tido até agora, do radicalismo, do } \\
\text { ódio, do preconceito, que não vai levar a nada. }\end{array}$ & Mudança \\
\hline \multirow[b]{2}{*}{ Alvaro } & Ex. 31 & Quero mudar o Brasil com seu apoio. & Mudança \\
\hline & Ex. 32 & $\begin{array}{l}\text { Trabalharei duro quatro anos para deixar um legado de } \\
\text { mudança para o povo brasileiro, especialmente para os } \\
\text { pobres desse país. }\end{array}$ & Trabalho duro \\
\hline Ciro & Ex. 33 & $\begin{array}{l}\text { Essa divisão não vai permitir que o Brasil supere a sua } \\
\text { crise. Essa divisão tende a aprofundar essa crise grave e } \\
\text { nós temos clareza hoje. }\end{array}$ & País unido \\
\hline Meirelles & Ex. 34 & $\begin{array}{l}\text { O que o Brasil precisa agora é de confiança, porque } \\
\text { confiança traz crescimento, traz emprego, traz renda. }\end{array}$ & Confiança \\
\hline Haddad & Ex. 35 & $\begin{array}{l}\text { Portanto, as minhas obsessões durante os quatro anos de } \\
\text { mandato vão ser trabalho e educação para todos. }\end{array}$ & $\begin{array}{l}\text { Trabalho e } \\
\text { educação }\end{array}$ \\
\hline Marina & Ex. 36 & $\begin{array}{l}\text { estou aqui porque eu sei que eu sou a melhor pessoa para } \\
\text { o unir o Brasil e eu estou pronta para governar o Brasil } \\
\text { e unir os brasileiros a favor de um Brasil próspero para } \\
\text { todos. }\end{array}$ & $\begin{array}{l}\text { País unido; } \\
\text { Prosperidade }\end{array}$ \\
\hline \multirow{2}{*}{ Boulos } & Ex. 37 & $\begin{array}{l}\text { Nós só vamos mudar o Brasil enfrentando de verdade os } \\
\text { privilégios e mudando o jeito de fazer política. }\end{array}$ & Mudança \\
\hline & Ex. 38 & Vote com esperança, vote Boulos 50. & Esperança \\
\hline
\end{tabular}

Fonte: Elaborado pelas autoras.

Percebemos, por meio do Quadro 3, que os candidatos possuem imaginários distintos para o país que pretendem governar, tendo como recorrência apenas as categorias de "mudança", "união" e "trabalho". Em relação à predominância de "mudança", pressupomos que o que está posto no imaginário dos candidatos é que atualmente há problemas no país, os quais precisam ser resolvidos. Sobre a categoria "união", podemos inferir que o país está desunido e concluir que a atual divisão diz respeito ao fato de que as eleições em 2018 foram marcadas pela disputa explicitamente polarizada entre direita e esquerda, o que, de acordo com os imaginários dos políticos, não é favorável para o país. Por fim, a categoria "trabalho" denota um imaginário de ação, revelando que os políticos serão participantes ativos a favor do país e dos brasileiros. 


\section{CONSIDERAÇõES FINAIS}

A partir do trabalho realizado, constatamos que a análise do sistema de transitividade, do sistema de avaliatividade e de imaginários permitem identificar a forma como são construídas representações. Nesta pesquisa, investigamos como candidatos à presidência do Brasil representaram e avaliaram a si próprios, o povo e o país que pretendiam governar, bem como construíram imaginários relacionados a seus possíveis governos. A análise evidenciou que cada um empregou diferentes recursos discursivos para se mostrar como melhor opção de voto para governar o país. A Figura 2 resume os resultados obtidos.

Figura 2: Ocorrências das categorias

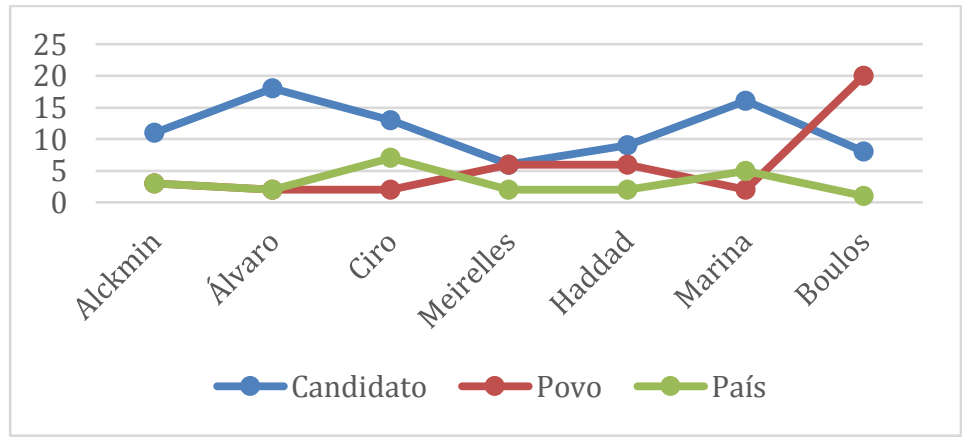

Fonte: Elaborada pelas autoras.

Por meio das escolhas linguísticas, identificamos que Alckmin, Alvaro, Ciro e Marina centram-se em atribuir à própria figura a condição de serem eleitos e capazes de governar o país. Dentre eles, Alckmin e Alvaro sobressaem-se como participantes Ator de característica tenaz, ou seja, como agentes persistentes e capazes de promover a mudança de que o país necessita. Ciro e Marina representam-se como políticos ou experientes ou portadores de atributos suficientes para levar adiante um projeto de governo. Entretanto, cabe a Boulos colocar o povo como o grande Ator no processo imaginado de mudança e trabalho necessários para que o país continue sua trilha de desenvolvimento. Ele se avalia como candidato capaz, persistente, grato pela ajuda que recebe e confiante no projeto de governo que pretende colocar em ação.

Os resultados que obtivemos demonstram a necessidade cada vez mais premente de, ao presenciarmos falas proferidas por candidatos, prestarmos atenção e adotarmos posturas mais reflexivas e críticas que permitam embasar nossas escolhas como eleitores. 


\section{REFERÊNCIAS}

BOCHETT, A. C. et al. Concepções de discurso político: caminhos para uma discussão teórica. Moara, v. 47, p. 128-151, 2017.

DENZIN, N, K.; LINCOLN, Y. S. O planejamento da pesquisa qualitativa: teorias e abordagens. Trad. Sandra Regina Nentz. Porto Alegre: Artmed, 2006.

FREITAS, J. C.; CABRAL, S. R. S. Avaliatividade: marcas linguísticas em exemplares do gênero exposição. In: CABRAL, S. R. S.; BARBARA, L. (org.). Estudos Sistêmico-Funcionais no âmbito do projeto SAL. Santa Maria: Programa de Pós-Graduação em Letras, 2018, v. 1, p. 230251.

HALLIDAY, M. A. K.; HASAN, R. Language, Context and Text: aspects of language in a socialsemiotic perspective. Oxford: Oxford University Press, 1985.

HALLIDAY, M. A. K.; MATTHIESSEN, C. Halliday's Introduction to Functional Grammar. London New York: Routledge, 2014.

JESSOP, B. Cultural political economy and critical policy studies. Critical Policy Studies, v, 3, p. 336-356, 2010.

JESSOP, B. Recovered imaginaries, imagined recoveries: A cultural political economy of crisis construals and crisis management in the north atlantic financial crisis. In: BENNER, M. (ed.). Before and beyond the global economic crisis. Cheltenham: Edward Elgar Publishing Limited, 2013, p. 234-254.

MARTIN, J. R.; WHITE, P. The language of evaluation: appraisal in English. New York: Palgrave, 2005.

WODAK, R. The discourse of politics in action. London: Palgrave, 2009. 